\title{
Endogenous Adenosine Inhibits P-Selectin-dependent Formation of Coronary Thromboemboli during Hypoperfusion in Dogs
}

\author{
Tetsuo Minamino, ${ }^{\star}$ Masafumi Kitakaze, ${ }^{*}$ Hiroshi Asanuma, ${ }^{*}$ Yoshiaki Tomiyama, ${ }^{\ddagger}$ Masamichi Shiraga, ${ }^{\ddagger}$ Hiroshi Sato, ${ }^{\star}$ \\ Yasunori Ueda, ${ }^{\star}$ Hiroharu Funaya, ${ }^{*}$ Tsunehiko Kuzuya, ${ }^{\star}$ Yuji Matsuzawa, ${ }^{\ddagger}$ and Masatsugu Hori ${ }^{\star}$ \\ The *First Department and ${ }^{\ddagger}$ Second Department of Medicine, Osaka University School of Medicine, Suita, Osaka 565, Japan
}

\begin{abstract}
The activation of platelets and the formation of neutrophilplatelet conjugates may lead to the development of thromboemboli. We studied whether blockade of adenosine receptors during coronary hypoperfusion may cause thromboemboli via P-selectin-dependent mechanisms in 30 open-chest dogs. When coronary blood flow was reduced to $20 \%$ of the control, it was stable at low levels with increases in adenosine levels. When 8- $p$-sulfophenyltheophylline, an adenosine receptor antagonist, was infused during coronary hypoperfusion, coronary blood flow decreased gradually and approached almost zero $20 \mathrm{~min}$ after its administration. Histological examination revealed thromboemboli in the small coronary vessels. During hypoperfusion in the presence of 8-p-sulfophenyltheophylline, the mAb against P-selectin attenuated both the reduction in coronary blood flow and the formation of thromboemboli, and improved contractile and metabolic dysfunction of the myocardium. Flow cytometric analysis indicated that the expression of P-selectin on platelet and neutrophil-platelet adhesion were increased during coronary hypoperfusion, and that both were further augmented by 8-p-sulfophenyltheophylline. Immunohistochemical examination showed no staining of P-selectin in the ischemic myocardium. Adenosine inhibited the thrombininduced expression of P-selectin on platelet and neutrophilplatelet adhesion via adenosine $\mathrm{A}_{2}$ receptors. Adenosine appears to inhibit the formation of thromboemboli during coronary hypoperfusion by suppressing the expression of P-selectin on platelets and neutrophil-platelet adhesion. ( $\mathrm{J}$. Clin. Invest. 1998. 101:1643-1653.) Key words: neutrophilplatelet adhesion - platelet • 8-p-sulfophenyltheophylline • ischemia $\bullet$ small coronary vessel
\end{abstract}

\section{Introduction}

Adenosine modifies several important cellular processes in the cardiovascular system $(1,2)$ : it relaxes vascular smooth muscle, inhibits both the aggregation of platelets and the generation of superoxide anion by neutrophils, and prevents the adhesion of

Address correspondence to Masafumi Kitakaze, M.D., Ph.D., The First Department of Medicine, Osaka University School of Medicine, 2-2 Yamadaoka, Suita, Osaka 565, Japan. Phone: 81-6-879-3635; FAX: 81-6-879-3645; E-mail: kitakaze@medone.med.osaka-u.ac.jp

Received for publication 14 May 1997 and accepted in revised form 16 February 1998.

J. Clin. Invest.

(C) The American Society for Clinical Investigation, Inc. 0021-9738/98/04/1643/11 \$2.00

Volume 101, Number 8, April 1998, 1643-1653

http://www.jci.org neutrophils to the endothelium. The production of adenosine increases markedly in the ischemic myocardium (3). The various physiological effects of adenosine act synergistically to maintain coronary blood flow $(\mathrm{CBF})^{1}(4)$ and to attenuate myocardial injury due to ischemia and reperfusion $(5,6)$.

Adhesion molecules facilitate the interaction between neutrophils, platelets, and endothelial cells $(7,8)$. P-selectin is an important adhesion molecule found in the secretory granules of platelets and the Weibel-Palade bodies of endothelial cells (9). P-selectin is mobilized rapidly to the plasma membrane 5-10 min after stimulation with inflammatory mediators (9). P-selectin mediates the neutrophil-platelet (10) and neutrophil-endothelial cell (11) interactions. Since the activation of platelets, the formation of neutrophil-platelet conjugates, and the adhesion of neutrophils to the endothelium may lead to the development of thromboemboli $(12,13)$, P-selectin expressed on platelets and/or endothelial cells may be involved in the formation of thromboemboli found in ischemia/reperfused myocardium $(14,15)$. Recent studies demonstrated that P-selectin plays an important role in the extension of myocardial infarct (16) and in the no-reflow phenomenon (17). However, it has not been determined whether or how P-selectin on platelets and/or endothelial cells is involved in the formation of thromboemboli, or in contractile and metabolic dysfunction of the myocardium during coronary hypoperfusion. Since adenosine is increased markedly in the ischemic myocardium, and since adenosine inhibits the activation of platelets (17) and the adhesion of neutrophils to the endothelium (18), we hypothesized that an increased level of adenosine during coronary hypoperfusion may inhibit the formation of thromboemboli by suppressing the expression of P-selectin on platelets and/or endothelial cells. To test this idea, we examined $(a)$ the effects of an adenosine receptor antagonist on $\mathrm{CBF}$, contractile and metabolic function of the myocardium, and the formation of thromboemboli during coronary hypoperfusion and the role of $\mathrm{P}$-selectin in this condition using an $\mathrm{mAb}$ against $\mathrm{P}$-selectin; (b) whether P-selectin on platelets or endothelial cells, or both, is involved in the formation of thromboemboli during coronary hypoperfusion; $(c)$ the effects of an adenosine receptor antagonist on the expression of P-selectin on platelet and on neutrophil-platelet adhesion and the role of P-selectin in this adhesion; and $(d)$ whether adenosine attenuates the thrombininduced expression of P-selectin on platelets and neutrophilplatelet adhesion via adenosine $\mathrm{A}_{1}$ or $\mathrm{A}_{2}$ receptors in the in vitro experiments.

1. Abbreviations used in this paper: $\mathrm{CBF}$, coronary blood flow; $\mathrm{CHA}$, cyclohexyladenosine; CPP, coronary perfusion pressure; FS, fractional shortening; LAD, left anterior descending coronary artery; LCX, left circumflex coronary artery; LER, lactate extraction ratio; $\mathrm{MVO}_{2}$, myocardial oxygen consumption; PRP, platelet-rich plasma; 8-SPT, 8-p-sulfophenyltheophylline. 


\section{Methods}

\section{Materials}

Adenosine, cyclohexyladenosine (CHA), 8-p-sulfophenyltheophylline (8-SPT), bovine thrombin, paraformaldehyde, and sodium citrate were all obtained from Sigma Chemical Co. (St. Louis, MO). CGS21680C was kindly donated by Ciba-Geigy Corp. (Summit, NJ). $\mathrm{mAb}$ against $\mathrm{P}$-selectin (CY1747, mouse $\mathrm{IgG}_{1}$; also known as PB1.3) was kindly donated by Sumitomo Pharmaceuticals Co., Ltd. (Osaka, Japan). We and other authors (19) have confirmed that CY1747 recognizes P-selectin expressed on canine platelets that were activated by thrombin $(0.25 \mathrm{U} / \mathrm{ml})$ (Fig. 1). mAb against CD41 (MCA1471, mouse $\mathrm{IgG}_{2 \mathrm{a}}$ ), which is commonly and specifically expressed on the surface of canine platelets (20), FITC-conjugated goat antibody against mouse $\mathrm{IgG}_{1}$, FITC-conjugated sheep antibody against mouse $\mathrm{IgG}_{2 \mathrm{a}}$, and negative isotopic $\mathrm{mAbs}$ were all purchased from Serotec Ltd. (Oxford, UK). FACS ${ }^{\circledR}$ lysing solution was purchased from Becton Dickinson (San Jose, CA).
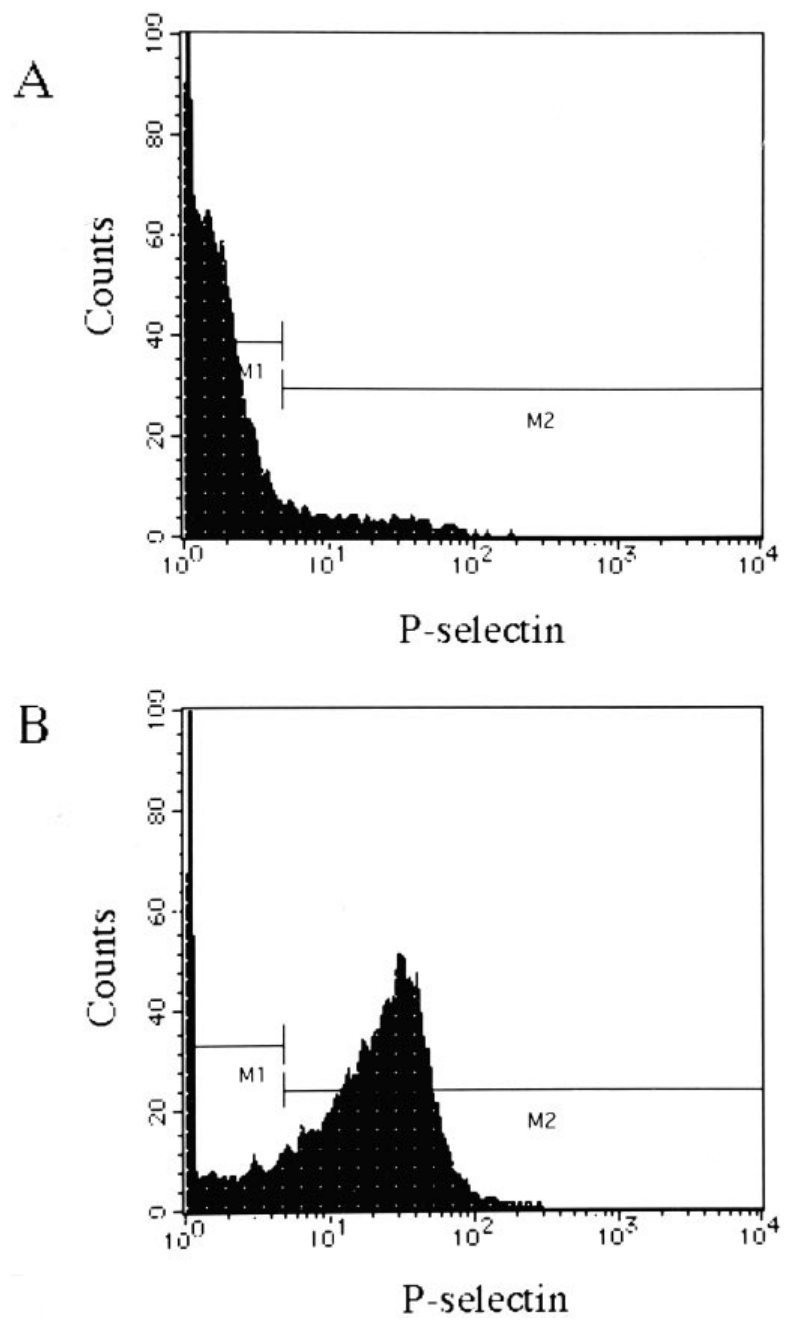

Figure 1. Cross-reactivity of CY1747 with canine platelets. Canine platelets treated without $(A)$ and with $(B)$ thrombin $(0.25 \mathrm{U} / \mathrm{ml})$. Horizontal bars of M1 and M2, Negative and positive portions, respectively. The percentages of platelets that expressed P-selectin in $A$ and $B$ were 8.7 and $79.2 \%$, respectively. Rightward shift of canine platelets with thrombin indicated that CY1747 can recognize P-selectin on canine platelets.

\section{Instrumentation}

30 mongrel dogs of either sex (14-19 kg) were anesthetized with pentobarbital sodium $(30 \mathrm{mg} / \mathrm{kg})$. The trachea was intubated, and the animal was ventilated with room air supplemented with oxygen. The chest was opened through the left fifth intercostal space, and the heart was suspended in a pericardial cradle. After heparinization (500 $\mathrm{U} / \mathrm{kg}$ ), the left anterior descending coronary artery (LAD) was cannulated and perfused with blood via the carotid artery through an extracorporeal bypass tube. The cannulation procedure was performed within $10 \mathrm{~s}$. The coronary hemodynamic parameters returned to baseline within $10 \mathrm{~min}$ after the end of cannulation. Data collection was then begun. $\mathrm{CBF}$ was measured with an electromagnetic flow probe attached to the bypass tube. Coronary perfusion pressure (CPP) was monitored at the tip of the coronary arterial cannula. A small collecting tube was inserted into a small coronary vein near the center of the perfused area to sample coronary venous blood. The drained venous blood was collected in a reservoir placed at the level of the left atrium. Precise values of left ventricular pressure and its first derivative were measured with a micromanometer (Model P-5; Konigsberg Instruments, Inc., Pasadena, CA) placed in the left ventricular cavity through the apex of the heart. A pair of ultrasonic crystal probes was placed in the center of the perfused area to allow the measurement of myocardial segment length with an ultrasonic dimension gauge (5 $\mathrm{MHz}$; Schuessler, Cardiff by the Sea, CA). End-diastolic length was determined at the $\mathrm{R}$ wave of the electrocardiogram, and end-systolic length was determined at the minimal $\mathrm{dP} / \mathrm{dt}$. Fractional shortening (FS) was calculated by the formula [(end-diastolic length) - (end-systolic length)]/(end-diastolic length) and served as an index of myocardial contractility of the perfused area.

\section{Study protocols}

Protocol 1. Effects of blockade of adenosine receptors on CBF, CPP, $P$-selectin on platelets, and neutrophil-platelet adhesion. After confirmation of the hemodynamic stabilization, CPP was reduced with an occluder attached to the bypass tube until CBF decreased to $20 \%$ of the control flow. When the decrease in CPP was confirmed, the occluder was adjusted manually to maintain $\mathrm{CPP}$ at a constant low level for $20 \mathrm{~min}$ (control group, $n=5$ ). To examine the role of adenosine in the maintenance of CBF during coronary hypoperfusion, the same procedures as in the control group were performed $5 \mathrm{~min}$ after the onset of administration of 8 -SPT $(25 \mu \mathrm{g} / \mathrm{kg} / \mathrm{min})$, an adenosine receptor antagonist, into the LAD (8-SPT [H] group, $n=5)$. We also evaluated the effects of 8 -SPT at different doses $(2.5 \mu \mathrm{g} / \mathrm{kg} / \mathrm{min}: 8$-SPT [M] group, $n=5 ; 0.25 \mu \mathrm{g} / \mathrm{kg} / \mathrm{min}$ : 8-SPT [L] group, $n=5$ ) on coronary hemodynamic variables during coronary hypoperfusion as in the 8-SPT $(\mathrm{H})$ group. In addition, we evaluated the effects of the intracoronary administration of 8 -SPT $(25 \mu \mathrm{g} / \mathrm{kg} / \mathrm{min})$ for $20 \mathrm{~min}$ on coronary hemodynamic variables under normal conditions $(n=5)$. To examine the role of P-selectin in the reduction of CBF due to 8-SPT treatment, the same procedures as in the control group were performed $5 \mathrm{~min}$ after the onset of the coadministration of $\mathrm{mAb}$ against P-selectin (CY1747, $2 \mu \mathrm{g} / \mathrm{kg} / \mathrm{min})$ and 8-SPT $(25 \mu \mathrm{g} / \mathrm{kg} / \mathrm{min})$ into the LAD (the 8-SPT plus CY1747 group, $n=5$ ). The concentrations of CY1747 in the LAD-perfused myocardium during coronary hypoperfusion ranged from 5 to $10 \mu \mathrm{g} / \mathrm{ml}$. CPP, CBF, and the segment lengths in the LAD-perfused area were monitored throughout the experiment. Blood was withdrawn from the bypass tube immediately proximal to the insertion point to the LAD and from the coronary vein in the LAD-perfused myocardium. Blood samples were obtained before and $3,5,10$, and $15 \mathrm{~min}$ after the onset of coronary hypoperfusion. We analyzed blood gas, measured lactate and adenosine levels, and evaluated the expression of P-selectin on platelets and neutrophilplatelet adhesion. After measuring the hemodynamic parameters and sampling blood, the partial occlusion of the bypass tube was released. After confirming that coronary hemodynamic parameters had stabilized, the heart was prepared for histological and immunohistochemical examination. 
Protocol 2. Expression of P-selectin on the endothelium of the ischemic myocardium. Since P-selectin is expressed on the endothelial cells as well as on platelets (9), we examined immunohistochemically the expression of P-selectin on the endothelium in the LADand left circumflex coronary artery (LCX)-perfused myocardium. We obtained myocardial samples $20 \mathrm{~min}$ after the onset of coronary hypoperfusion with and without 8-SPT. Weyrich et al. (15) have shown that $\mathrm{P}$-selectin is stained in the ischemic myocardium after 90 min of coronary occlusion followed by $20 \mathrm{~min}$ of reperfusion. Thus, we completely occluded the LAD for 90 min followed by $20 \mathrm{~min}$ of reperfusion and obtained the LAD-perfused myocardium as a positive control in four dogs.

Protocol 3. Effects of adenosine on expression of P-selectin on platelets and on neutrophil-platelet adhesion in vitro. To determine whether the blockade of adenosine receptors may increase the expression of P-selectin on platelets due to its primary effects on the platelets, or to its secondary effects on the worsening of myocardial ischemia, we examined the effects of adenosine on the thrombininduced expression of P-selectin on platelets and neutrophil-platelet adhesion in vitro. Peripheral venous blood was collected from the left jugular vein of five dogs into the syringe tube containing $3.8 \%$ sodium citrate. To prevent clotting through the binding of fibrinogen-IIb/ IIIa, samples were incubated with Arg-Gly-Asp-Ser (Peninsula Laboratories Inc., Belmont, CA) at a final concentration of $1 \mathrm{mg} / \mathrm{ml}$. Samples were divided into two parts for determining the percentage of platelets that expressed P-selectin and of neutrophils that bound to platelets. To evaluate the expression of P-selectin on platelets, platelet-rich plasma (PRP) was prepared by centrifuging blood at $150 \mathrm{~g}$ for $15 \mathrm{~min}$ at $22^{\circ} \mathrm{C}$. To evaluate neutrophil-platelet adhesion, whole blood was incubated with $\mathrm{FACS}^{\circledR}$ lysing solution for $10 \mathrm{~min}$ at room temperature to lyse erythrocytes, washed twice, and resuspended in Dulbecco's PBS. PRP or erythrocyte-lysed blood (100 $\mu \mathrm{l})$ was incubated in polypropylene tubes containing adenosine $\left(10^{-9}, 10^{-7}\right.$, and $10^{-5} \mathrm{~mol} /$ liter $)$, CHA $\left(10^{-8} \mathrm{~mol} /\right.$ liter $)$, or CGS21680C $\left(10^{-8} \mathrm{~mol} /\right.$ liter $)$ at $37^{\circ} \mathrm{C}$ for $10 \mathrm{~min}$ followed by the incubation with thrombin $(0.1 \mathrm{U} / \mathrm{ml})$ at $37^{\circ} \mathrm{C}$ for $10 \mathrm{~min}$. The doses of CHA and CGS21680C used in this study selectively stimulate adenosine $A_{1}$ and $A_{2}$ receptors, respectively $(21,22)$. The percentage of platelets that expressed P-selectin in PRP and of neutrophils that bound to platelets in erythrocyte-lysed blood were determined by flow cytometric analysis. To examine whether P-selectin is involved in neutrophil-platelet adhesion, we evaluated the effects of CY1747 $(10 \mu \mathrm{g} / \mathrm{ml})$ on the thrombin-induced increase in the percentage of neutrophils that bound to platelets as described above.

\section{Preparation of samples for flow cytometry}

In protocol 1, canine blood was collected from the small coronary vein into a syringe tube that contained sodium citrate $(0.38 \%$ final concentration). All blood samples were fixed immediately in $1 \%$ (final concentration) paraformaldehyde for $60 \mathrm{~min}$ at $4^{\circ} \mathrm{C}$, then washed with Dulbecco's PBS. Immediate fixation prevents the time-dependent expression of P-selectin. Preliminary experiments demonstrated the consistent binding of primary antibody after a 2-h period of fixation. Samples were divided into two parts for determination of the percentage of platelets that expressed P-selectin and of neutrophils that bound to platelets. After being prepared by centrifugation, PRP $(50 \mu \mathrm{l})$ was incubated with CY1747 $(20 \mu \mathrm{g} / \mathrm{ml})$ for $30 \mathrm{~min}$ on ice, washed twice, incubated with FITC-conjugated goat antibody against mouse $\mathrm{IgG}_{1}$ at a $1: 100$ dilution for $30 \mathrm{~min}$ at $4^{\circ} \mathrm{C}$, washed twice, and then resuspended in $400 \mu \mathrm{l}$ Dulbecco's PBS. Separate samples of whole blood $(100 \mu \mathrm{l})$ were incubated with saturating concentrations of anti-CD41 $\mathrm{mAb}(10 \mu \mathrm{g} / \mathrm{ml})$ for $30 \mathrm{~min}$ at $4^{\circ} \mathrm{C}$, washed twice, and then incubated with FITC-conjugated sheep antibody against mouse $\mathrm{IgG}_{2 \mathrm{a}}$ at a $1: 100$ dilution for $30 \mathrm{~min}$ at $4^{\circ} \mathrm{C}$. Samples were then incubated with a FACS ${ }^{\circledR}$ lysing solution for $10 \mathrm{~min}$ at room temperature to lyse erythrocytes, washed twice, and resuspended in $400 \mu \mathrm{l}$ Dulbecco's PBS. Isotopic mAbs were used to determine nonspecific background fluorescence in samples prepared in parallel.
In protocol 3, after the samples were stimulated with thrombin, they were washed with Dulbecco's PBS and fixed in paraformaldehyde ( $1 \%$ final concentration) for $60 \mathrm{~min}$ at $4^{\circ} \mathrm{C}$. After fixation, the expression of P-selectin on platelets and neutrophil-platelet adhesion were determined in the same manner as described above.

\section{$F A C S^{\circledR}$ analysis}

Samples were analyzed on a FACScan $^{\circledR}$ flow cytometer with CellQuest software (Becton Dickinson). The platelets were distinguished from leukocytes according to their logistic forward- and sidelight scatter profile. After a gate was set around the platelets, 10,000 platelets were collected for each sample. The percentage of platelets positive for P-selectin was determined by the number that exhibited FITC fluorescence $>99 \%$ of those platelets incubated with the nonspecific antibody (23). The percentage of neutrophils that bound to platelets was determined as described previously with minor modifications $(24,25)$. In brief, live-gating on neutrophil-sized events was performed using a combination of forward- and side-scatter. Subsets of leukocytes, i.e., monocytes, neutrophils, and lymphocytes, were identified according to these characteristics. The percentage of platelet marker-positive events (FITC-anti-CD41) in a neutrophil subset represents the percentage of neutrophils with at least one bound platelet. After a gate was set around the neutrophils, 5,000 neutrophils were collected for each sample.

\section{Quantitative analysis of plugging of coronary vessels}

We evaluated quantitatively the extent of plugging of coronary vessels as described previously with minor modifications (26). First, we identified coronary vessels in the myocardial sections of the experimental animals. We counted the numbers of small coronary arteries (lumen diameter 100-400 $\mu \mathrm{m}$ ) and coronary arterioles (lumen diameter 40-99 $\mu \mathrm{m}$ ), and expressed their density as the number per square millimeter. These procedures were carried out in 10 fields (at a magnification of 400) per dog. We then determined the percentage of areas that thromboemboli occupied in the vessel lumens using an image analysis computer program (NIH Image 1.60). We defined as "plugged" a vessel in which thromboemboli occupied $>80 \%$ of its lumen.

\section{Histological and immunohistochemical methods}

At the end of Protocol 1, hearts were perfused with oxygenated Krebs-Henseleit buffer via a bypass tube for $2 \mathrm{~min}$ at a pressure of 50 $\mathrm{mmHg}$ to remove unattached blood. The hearts were then removed. Samples were obtained from the endomyocardium perfused by the LAD and LCX, and were fixed with phosphate-buffered $10 \%$ formalin or were frozen rapidly in OCT (Miles, Inc., Elkhart, IN) using isopentane cooled with liquid nitrogen. Histological sections $(4 \mu \mathrm{m})$ were cut from tissue embedded in paraffin and stained with hematoxylin and eosin. Immunohistochemical staining of cryostat sections $(4 \mu \mathrm{m})$ was performed using CY1747 $(2.01 \mathrm{mg} / \mathrm{ml})$ as a primary antibody at dilutions of 1:200 for a positive control sample, and at dilutions of 1:50 for other samples. Antibody-binding sites were labeled using an avidin-biotin-peroxidase complex method (Vectastain ABC kit; Vector Laboratories, Inc., Burlingame, CA) (27).

\section{Chemical analysis}

The plasma concentration of lactate was determined enzymatically (3). The lactate extraction ratio (LER) was calculated according to the following formula:

$100 \times[$ (arterial lactate concentration) -

(venous lactate concentration) ] / (arterial lactate concentration) (3)

Blood gas analysis was performed with a blood gas analyzer (ABL300; Radiometer A/S, Copenhagen, Denmark). Myocardial oxygen consumption $\left(\mathrm{MVO}_{2}\right)(\mathrm{ml} / 100 \mathrm{~g} / \mathrm{min})$ was calculated as follows (3): $\mathrm{CBF}(\mathrm{ml} / 100 \mathrm{~g} / \mathrm{min}) \times$ the difference in blood oxygen content between coronary arterial and venous blood $(\mathrm{ml} / \mathrm{dl})$. The plasma levels of adenosine were measured as described previously (3). 


\section{Statistical analysis}

Data are expressed as mean \pm SEM. The time course of changes in hemodynamic parameters in each group was compared by one-way repeated measures ANOVA. The time course of changes in hemodynamic parameters between groups was compared by two-way repeated measures ANOVA. The percentages of platelets that expressed P-selectin, of neutrophils that bound to platelets, and of plugging in coronary vessels were compared by one-way factorial ANOVA and Bonferroni's test. A level of $P<0.05$ was accepted as statistically significant.

\section{Results}

Effects of blockade of adenosine receptors on systemic and coronary hemodynamics during coronary hypoperfusion. In the control group, the baseline heart rate, systolic blood pressure, CPP, CBF, LER, FS, and $\mathrm{MVO}_{2}$ were $142 \pm 5$ beats/min, $137 \pm 4 \mathrm{mmHg}, 106 \pm 4 \mathrm{mmHg}, 90 \pm 3 \mathrm{ml} / 100 \mathrm{~g} / \mathrm{min}, 21 \pm 2 \%$, $23 \pm 2 \%$, and $5.9 \pm 0.3 \mathrm{ml} / 100 \mathrm{~g} / \mathrm{min}$, respectively. There were no significant differences in these parameters before coronary hypoperfusion among the groups studied.
CBF was stable at low levels when CPP was adjusted manually to maintain a CPP at a constant low level in the control group (Fig. 2, $A$ and $B$ ). Coronary arteriovenous differences in the levels of adenosine $(16 \pm 5 \mathrm{pmol} / \mathrm{ml})$ were increased significantly $(P<0.05 ; 397 \pm 33 \mathrm{pmol} / \mathrm{ml}) 15 \mathrm{~min}$ after the onset of coronary hypoperfusion. When CPP was returned to control perfusion pressure after the release of the partial occlusion, $\mathrm{CBF}$ also returned to the prehypoperfusion level $(88 \pm 4 \mathrm{ml} / 100$ $\mathrm{g} / \mathrm{min}$ ) after a period of reactive hyperemia (peak $\mathrm{CBF}$, $344 \pm 39 \mathrm{ml} / 100 \mathrm{~g} / \mathrm{min})$. In the 8-SPT $(\mathrm{H})$ and 8 -SPT plus CY1747 groups, to decrease CBF to $20 \%$ of the control flow, we needed to decrease CPP to $47 \pm 3$ and $46 \pm 3 \mathrm{mmHg}$, respectively. These values exceeded significantly $(P<0.05)$ those in the control group (Fig. $2 A$ ). In the 8-SPT $(\mathrm{H})$ group, CBF decreased gradually $3 \mathrm{~min}$ after the onset of ischemia, although CPP remained constant (Fig. 2 B). CBF was virtually zero 20 min after the onset of coronary hypoperfusion. After removal of the occluder, reactive hyperemia was not observed, and $\mathrm{CBF}$ did not return to the control level $(7 \pm 3 \mathrm{ml} / 100 \mathrm{~g} / \mathrm{min})$. Administration of CY1747 with 8-SPT attenuated partially but significantly $(P<0.05)$ the reduction in $\mathrm{CBF}$ induced by
A

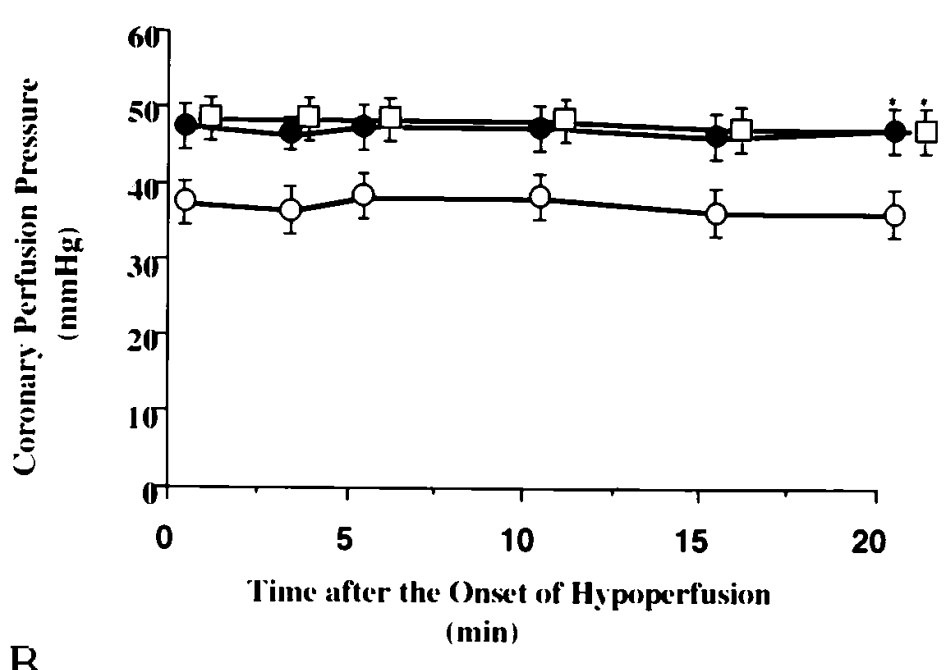

B

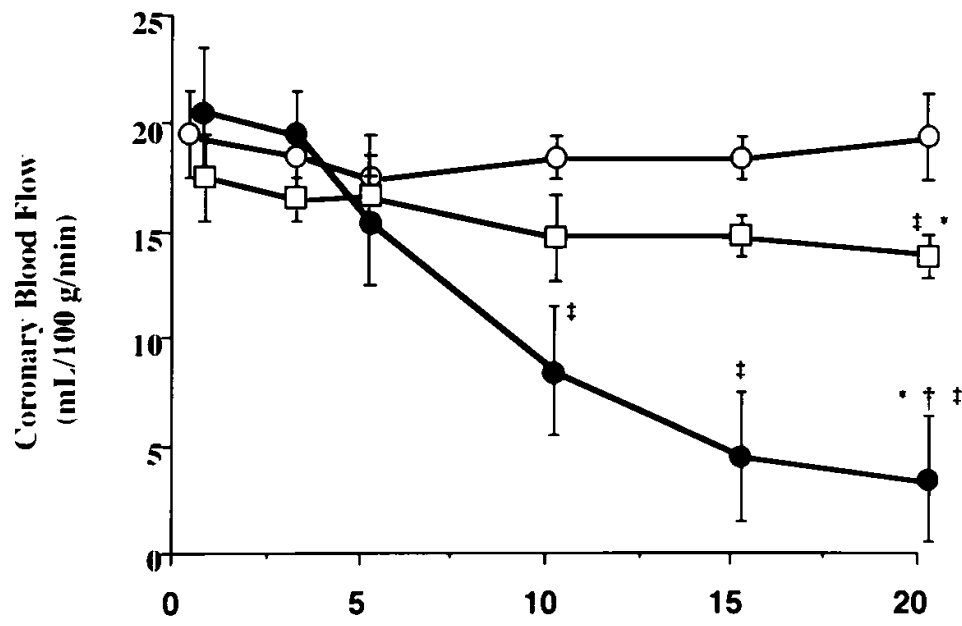

Time after the Onset of Hypoperfusion (min)
Figure 2. Effects of 8-SPT on CPP $(A)$ and $\mathrm{CBF}(B)$ during coronary hypoperfusion in dogs. CPP of the 8-SPT group (•) exceeded that of the control group $(O)$ when $\mathrm{CBF}$ was reduced to $20 \%$ of the control $(A)$. 8 -SPT gradually reduced CBF in 5-10 min, and approached almost zero 20 min after its administration $(B)$. CY1747 $(\square)$ blunted partially the reduction in CBF induced by 8 -SPT $(B)$. Each point represents the mean \pm SEM of five distinct experiments. $* P<0.05$ vs. control; ${ }^{\dagger} P<0.05$ vs. 8 -SPT $+\mathrm{CY} 174 ;{ }^{\ddagger} P<0.05$ vs. value at 0 min of each group. 


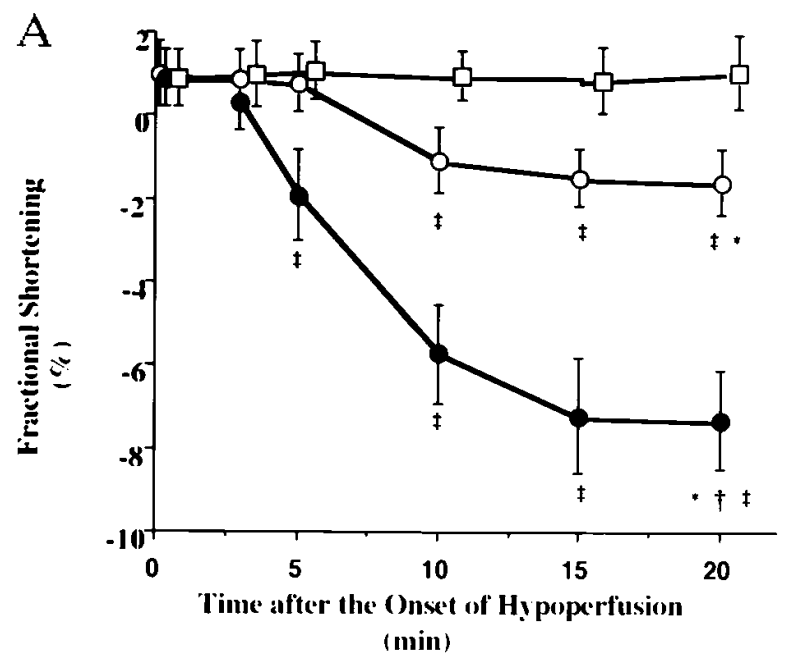

B

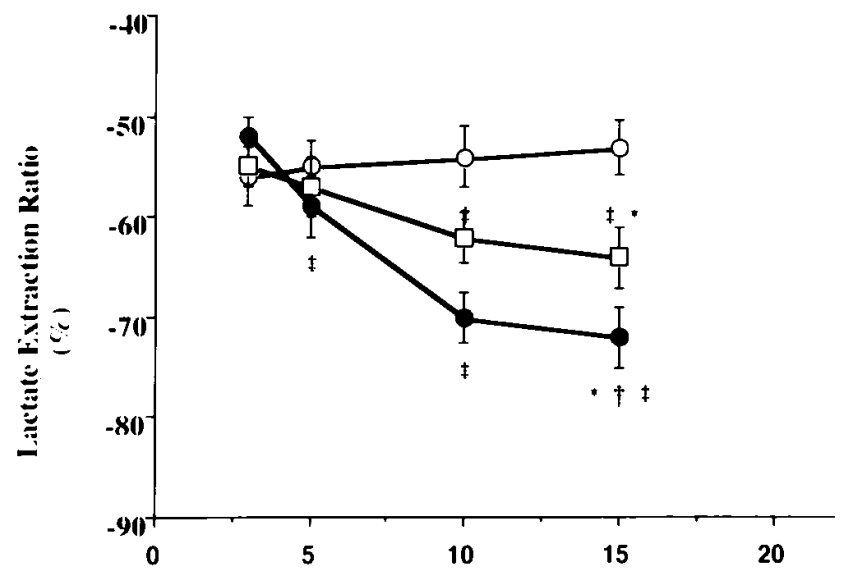

Time after the (Onset of Hypoperfision (min)

Figure 3. Effects of 8-SPT on FS $(A)$ and LER $(B)$ during coronary hypoperfusion in dogs. 8-SPT decreased FS and LER, both of which were attenuated partially by CY1747. Each point represents the mean \pm SEM of five distinct experiments. $\bigcirc$, Control. $\bullet, 8$-SPT. $\square$, 8-SPT plus CY1747. ${ }^{*} P<0.05$ vs. control; ${ }^{\dagger} P<0.05$ vs. 8 -SPT + CY1747; ${ }^{\ddagger} P<0.05$ vs. value at 0 min of each group.

8-SPT (Fig. 2 B). When CPP returned to the prehypoperfusion level in the 8-SPT plus CY1747 group, CBF returned to the normal value $(91 \pm 5 \mathrm{ml} / 100 \mathrm{~g} / \mathrm{min})$ after reactive hyperemia (peak CBF, $240 \pm 28 \mathrm{ml} / 100 \mathrm{~g} / \mathrm{min}$ ).

The intracoronary administration of 8 -SPT $(25 \mu \mathrm{g} / \mathrm{kg} / \mathrm{min})$ decreased $(P<0.05)$ both FS (Fig. $3 A$ ) and LER (Fig. $3 B$ ) compared with the control group. The 8-SPT-induced reductions in both FS (Fig. $3 A$ ) and LER (Fig. $3 B$ ) were attenuated partially but significantly $(P<0.05)$ by the coadministration of CY1747.

In the 8-SPT (M) and 8-SPT (L) groups, to decrease CBF to $20 \%$ of the control flow, we needed to decrease CPP to $46 \pm 3$ and $41 \pm 2 \mathrm{mmHg}$, respectively. The CPP of the 8-SPT $(\mathrm{M})$ group was higher $(P<0.05)$ than that of the control group (Fig. $4 A$ ). 8-SPT reduced CBF during coronary hypoperfusion in a dose-dependent manner (Fig. $4 B$ ). The intracoronary administration of 8 -SPT $(25 \mu \mathrm{g} / \mathrm{kg} / \mathrm{min})$ for $20 \mathrm{~min}$ under normal
CPP did not change the baseline CPP $(105 \pm 5 \mathrm{mmHg}), \mathrm{CBF}$ $(91 \pm 3 \mathrm{ml} / 100 \mathrm{~g} / \mathrm{min}), \mathrm{FS}(22 \pm 2 \%)$, LER $(23 \pm 2 \%)$, or $\mathrm{MVO}_{2}$ $(5.9 \pm 0.3 \mathrm{ml} / 100 \mathrm{~g} / \mathrm{min})$.

Expression of P-selectin on platelets and neutrophil-platelet adhesion during coronary hypoperfusion. Our preliminary studies confirmed that the systemic administration of heparin did not affect the percentage of platelets that expressed P-selectin $(6.4 \pm 0.7$ vs. $6.7 \pm 0.9 \%, n=4)$ or of the neutrophils bound to platelets $(13.3 \pm 1.1$ vs. $14.1 \pm 1.2 \%, n=4)$. We also confirmed that the percentage of platelets that expressed P-selectin (7.8 \pm 1.0 vs. $8.4 \pm 1.1 \%, n=4)$ or of neutrophils that bound to platelets $(11.4 \pm 0.8$ vs. $12.2 \pm 1.1 \%, n=4)$ did not change be-
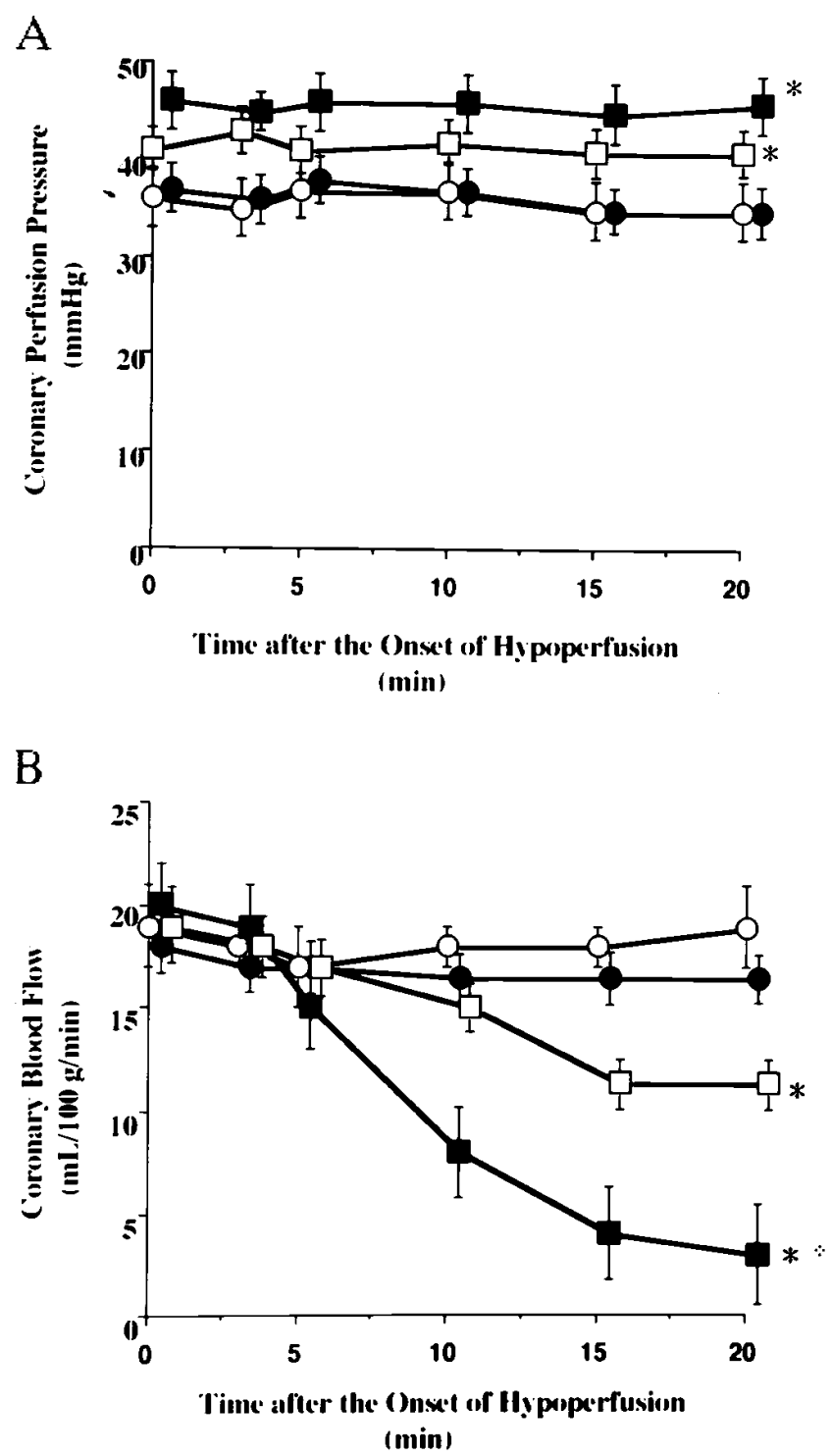

Figure 4. Dose-dependent responses of 8-SPT on CBF during coro-

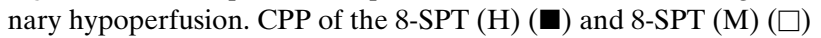
groups exceeded that of the control group $(\bigcirc)$ when $\mathrm{CBF}$ was reduced to $20 \%$ of the control $(A)$. 8 -SPT reduced CBF during coronary hypoperfusion in a dose-dependent manner $(B)$. Doses of 8-SPT administered intracoronarily in 8-SPT $(\mathrm{H}),(\mathrm{M})$, and $(\mathrm{L})(\bullet)$ groups were $25,2.5$, and $0.25 \mu \mathrm{g} / \mathrm{kg} / \mathrm{min}$, respectively. Each point represents the mean \pm SEM of five distinct experiments. $* P<0.05$ vs. control; ${ }^{\dagger} P<0.05$ vs. 8-SPT (M). 


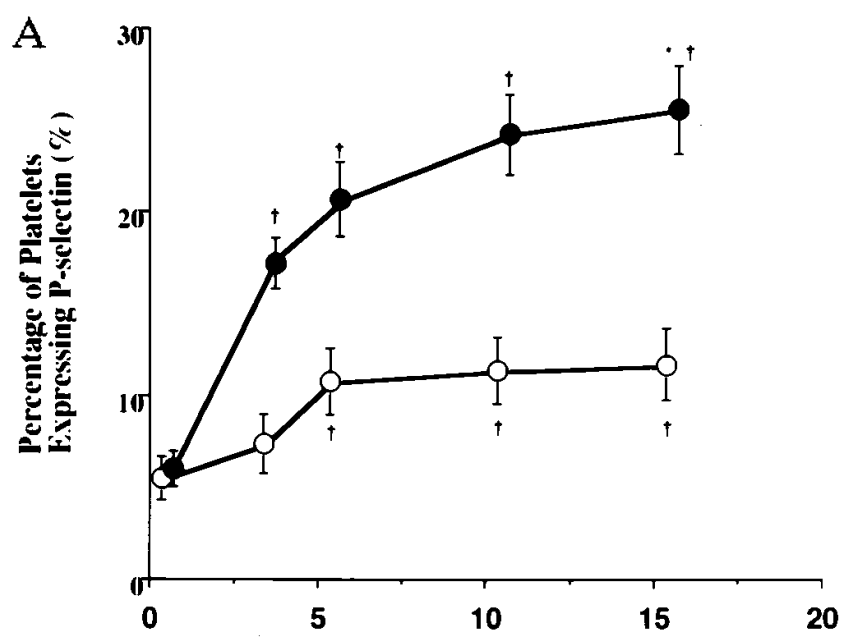

Time after the Onset of Hypoperfusion (min)

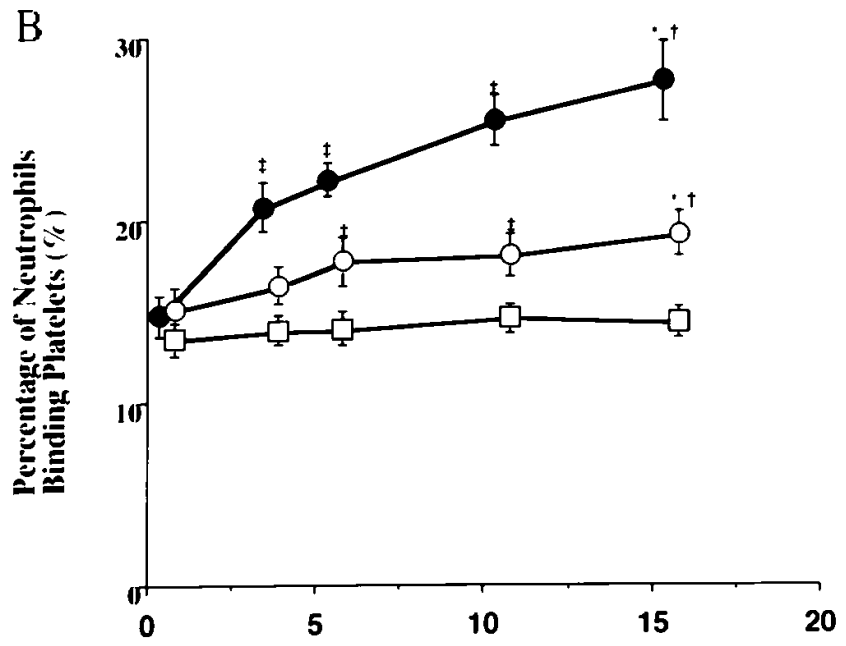

Time after the (Onset of Hypoperfusion (min)

Figure 5. Changes in the percentage of platelets that expressed P-selectin $(A)$ and of neutrophils that bound to platelets $(B)$ during coronary hypoperfusion in dogs. 8-SPT increased the percentage of platelets that expressed P-selectin and of neutrophils that bound to platelets during coronary hypoperfusion. CY 1747 partially inhibited the percentage of neutrophils that bound to platelets. Each point represents the mean \pm SEM of five distinct experiments. $\bigcirc$, Control; $\bullet$, 8-SPT; $\square, 8$-SPT plus CY1747. $* P<0.05$ vs. control $(A$ and $B) ;{ }^{\dagger} P<$ 0.05 vs. value at $0 \min (A) .{ }^{\dagger} P<0.05$ vs. 8 -SPT + CY1747 $(B) ;{ }^{\ddagger} P<$ 0.05 vs. value at $0 \mathrm{~min}$ of each group.

fore or $30 \mathrm{~min}$ after the cannulation of the coronary bypass tube. The percentage of platelets that expressed P-selectin and of neutrophils that bound to platelets showed a significant $(P<0.05)$ increase $5 \mathrm{~min}$ after the onset of coronary hypoperfusion and continued thereafter to increase (Fig. 5, $A$ and $B$ ). Both of these effects were augmented significantly by 8-SPT $(25 \mu \mathrm{g} / \mathrm{kg} / \mathrm{min}$ ) (Fig. 5, $A$ and $B$ ). The intracoronary administration of 8-SPT under baseline conditions for $20 \mathrm{~min}$ did not change the percentage of platelets that expressed P-selectin $(7.4 \pm 0.9$ vs. $8.3 \pm 1.0 \%)$ or of neutrophils that bound to platelets $(12.1 \pm 0.9$ vs. $12.6 \pm 1.0 \%)$.

Effects of $m A b$ against $P$-selectin on the formation of thromboemboli induced by blockade of adenosine receptors. Typical sections of myocardium showed that there were no abnormalities in the myocytes and coronary vessels in the LADperfused myocardium in the control group (Fig. $6 A$ ). In striking contrast, the 8-SPT-treated hearts exhibited a widespread plugging of the small coronary vessels (Fig. $6 \mathrm{~B}$ ) which was prevented by CY1747 (Fig. 6 C).

The densities of coronary small arteries in myocardial sections were $7 \pm 2 / \mathrm{mm}^{2}$ in the control group, $9 \pm 2 / \mathrm{mm}^{2}$ in the 8-SPT (H) group, $7 \pm 2 / \mathrm{mm}^{2}$ in the 8 -SPT (M) group, $9 \pm 2 / \mathrm{mm}^{2}$ in the 8 -SPT (L) group, and $9 \pm 1 / \mathrm{mm}^{2}$ in the 8 -SPT $(\mathrm{H})$ plus CY1747 group. The densities of coronary arterioles in myocardial sections were $48 \pm 3 / \mathrm{mm}^{2}$ in the control group, $46 \pm 5 / \mathrm{mm}^{2}$ in the 8-SPT $(\mathrm{H})$ group, $43 \pm 3 / \mathrm{mm}^{2}$ in the 8 -SPT (M) group, $44 \pm 4 / \mathrm{mm}^{2}$ in the 8 -SPT (L) group, and $46 \pm 5 / \mathrm{mm}^{2}$ in the 8 -SPT (H) plus CY1747 group. Quantitative data demonstrated that the intracoronary administration of 8-SPT increased the number of small coronary arteries and coronary arterioles that thromboemboli occupied in a dose-dependent manner (Fig. 7). CY1747 inhibited the formation of thromboemboli induced by 8-SPT (Fig. 7).

Expression of P-selectin on the endothelium in the ischemic myocardium. Endothelial P-selectin was evident in the small coronary artery of the ischemic (90 $\mathrm{min}) /$ reperfused $(20 \mathrm{~min})$ myocardium (positive control) (Fig. $8 \mathrm{~A}$ ). However, staining for P-selectin was not observed in the LCX-perfused myocardium (Fig. $8 \mathrm{~B}$ ). We also confirmed that P-selectin was not observed in the LAD-perfused myocardium 20 min after the onset of coronary hypoperfusion in the absence (Fig. $8 \mathrm{C}$ ) and presence (Fig. $8 D$ ) of 8 -SPT.

Effects of adenosine on thrombin-induced expression of $P$-selectin on platelets and neutrophil-platelet adhesion. Pretreatment with adenosine, CHA, or CGS21680C did not alter the percentage of platelets that expressed P-selectin or of neutrophils that bound to platelets under baseline conditions. Pretreatment with adenosine suppressed the thrombin-induced increase in the percentage of platelets that expressed P-selectin in a dose-dependent manner $\left(10^{-9} \mathrm{~mol} / \mathrm{liter}, 26 \pm 1 \% ; 10^{-7}\right.$ $\mathrm{mol} /$ liter, $\left.21 \pm 1 \% ; 10^{-5} \mathrm{~mol} / \mathrm{liter}, 12 \pm 1 \%\right)$. Pretreatment with adenosine suppressed the thrombin-induced increase in the percentage of neutrophils that bound to platelets in a dosedependent manner $\left(10^{-9} \mathrm{~mol} / \mathrm{liter}, 33 \pm 2 \% ; 10^{-7} \mathrm{~mol} / \mathrm{liter}, 24 \pm\right.$ $\left.2 \% ; 10^{-5} \mathrm{~mol} / \mathrm{liter}, 18 \pm 1 \%\right)$. Pretreatment with CGS21680C, not CHA, suppressed the thrombin-induced increase in the percentage of platelets that expressed P-selectin (Fig. $9 A$ ) and of neutrophils that bound to platelets (Fig. 9 B). CY1747 inhibited significantly the thrombin-induced increase in the percentage of neutrophils that bound to platelets (Fig. $9 \mathrm{~B}$ ).

\section{Discussion}

Effects of adenosine on coronary circulation and myocardial function during hypoperfusion. This study demonstrated that CBF decreased gradually in 5-10 min, and approached almost zero 20 min after the onset of hypoperfusion when 8-SPT was administered. Since adenosine is a potential coronary vasodilator $(1,2)$, and since these histological examinations revealed the presence of thromboemboli in the small coronary vessels, reduction in $\mathrm{CBF}$ by 8-SPT is considered to be due to functional changes in the coronary smooth muscle (e.g., vasoconstriction) and/or to the formation of thromboemboli in the 

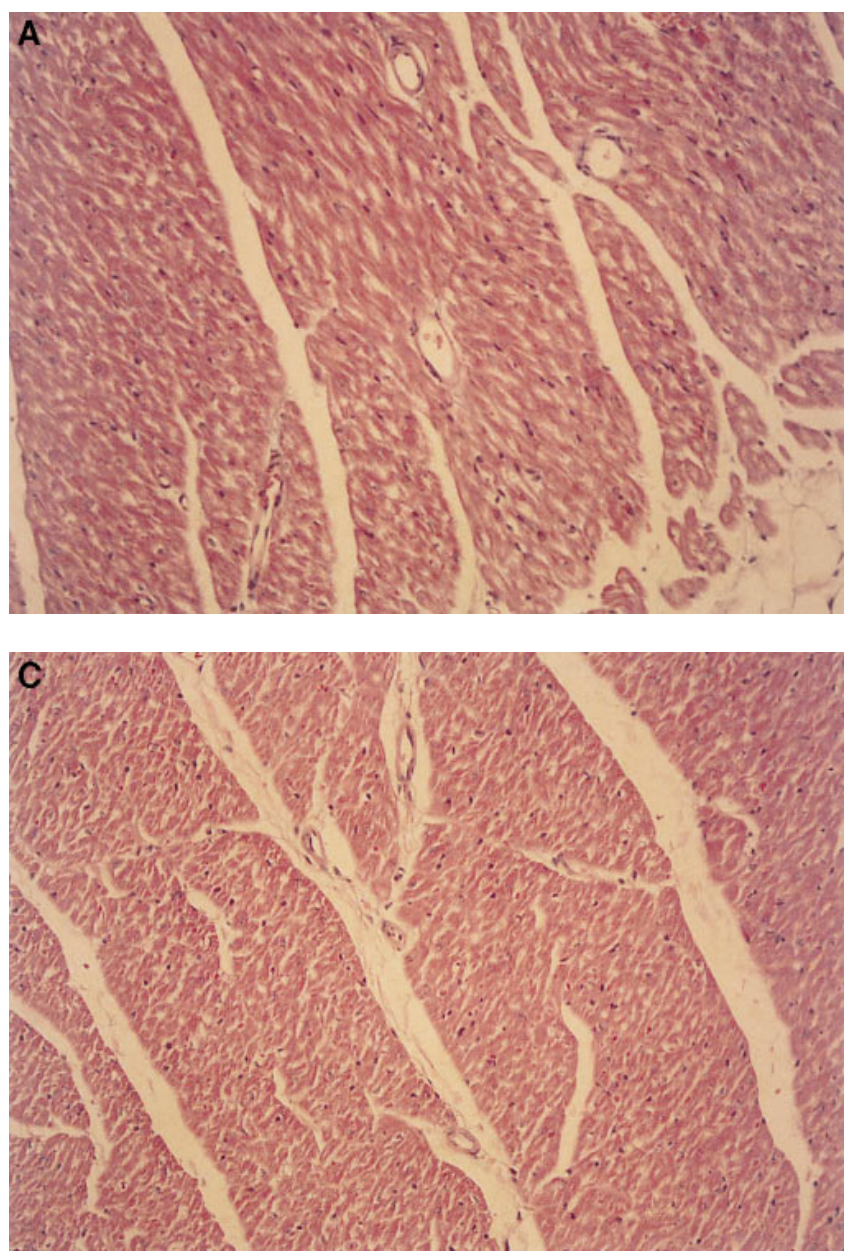

small coronary vessels. The latter seems more likely, since CBF did not return to baseline after the release of occlusion of the coronary bypass tube, and since $\mathrm{mAb}$ against P-selectin virtually abolished the reduction in CBF by 8 -SPT. These find-

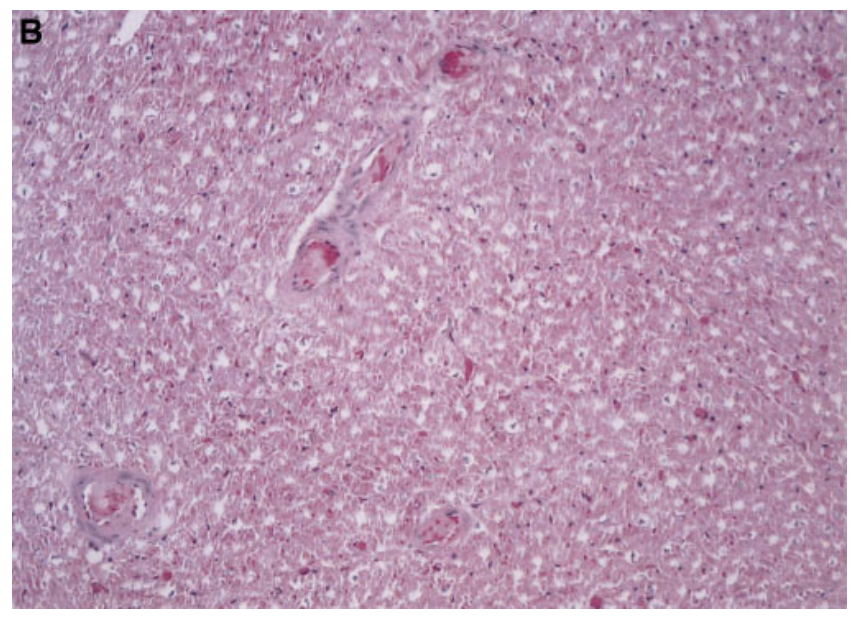

Figure 6. Representative photomicrographs showing hematoxylin and eosin staining in the canine myocardium perfused by the LAD in the control group $(A)$, the 8-SPT group $(B)$, and the 8-SPT plus CY1747 group $(C)$. Original magnification $\times 200$. Thromboemboli were found in the small coronary vessels of the 8-SPT group. The addition of CY1747 prevented the formation of such thromboemboli.

ings suggest that adenosine has an endogenous antithrombotic role in the ischemic myocardium.

The blockade of adenosine receptors during coronary hypoperfusion decreased FS and LER, indices of contractility
Small coronary arteries

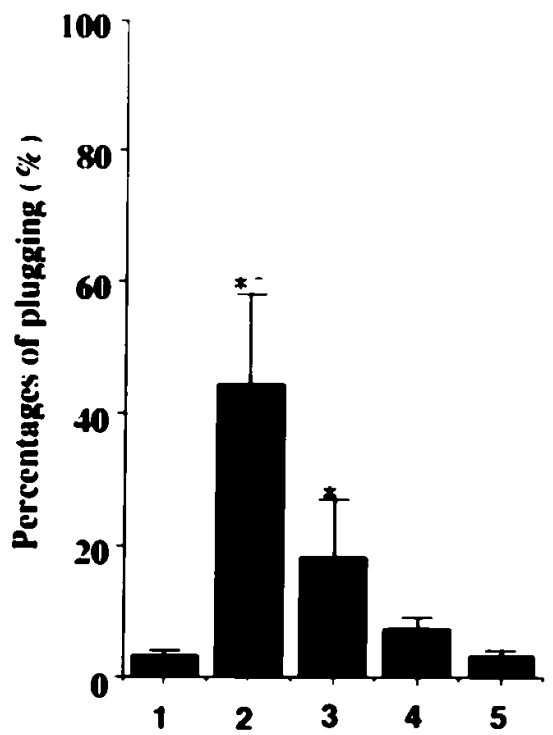

\section{Coronary arterioles}

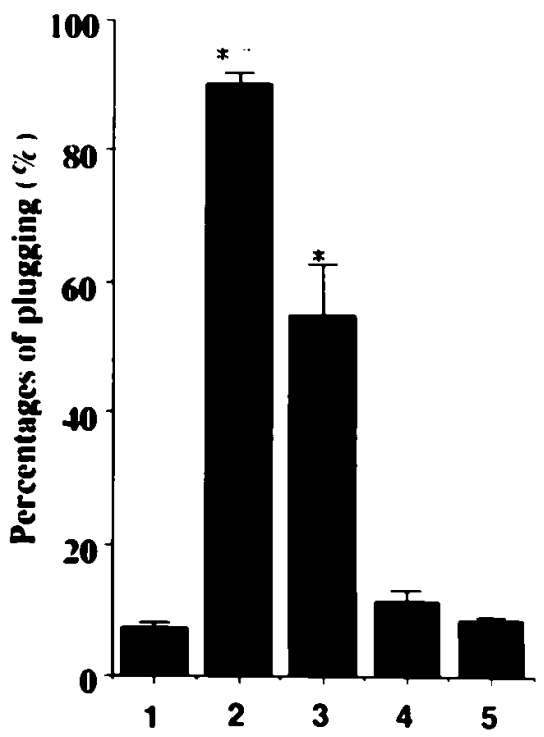

Figure 7. Quantitative analysis of coronary vessel pluggings. 8-SPT induced the formation of coronary vessel pluggings in coronary small arteries and arterioles. CY1747 inhibited the formation of coronary vessel pluggings induced by 8-SPT. Each bar represents the mean \pm SEM of five distinct experiments. 1, Control. 2, 8-SPT (H). 3, 8-SPT (M). 4, 8-SPT (L). 5, 8-SPT (H) plus CY1747. 

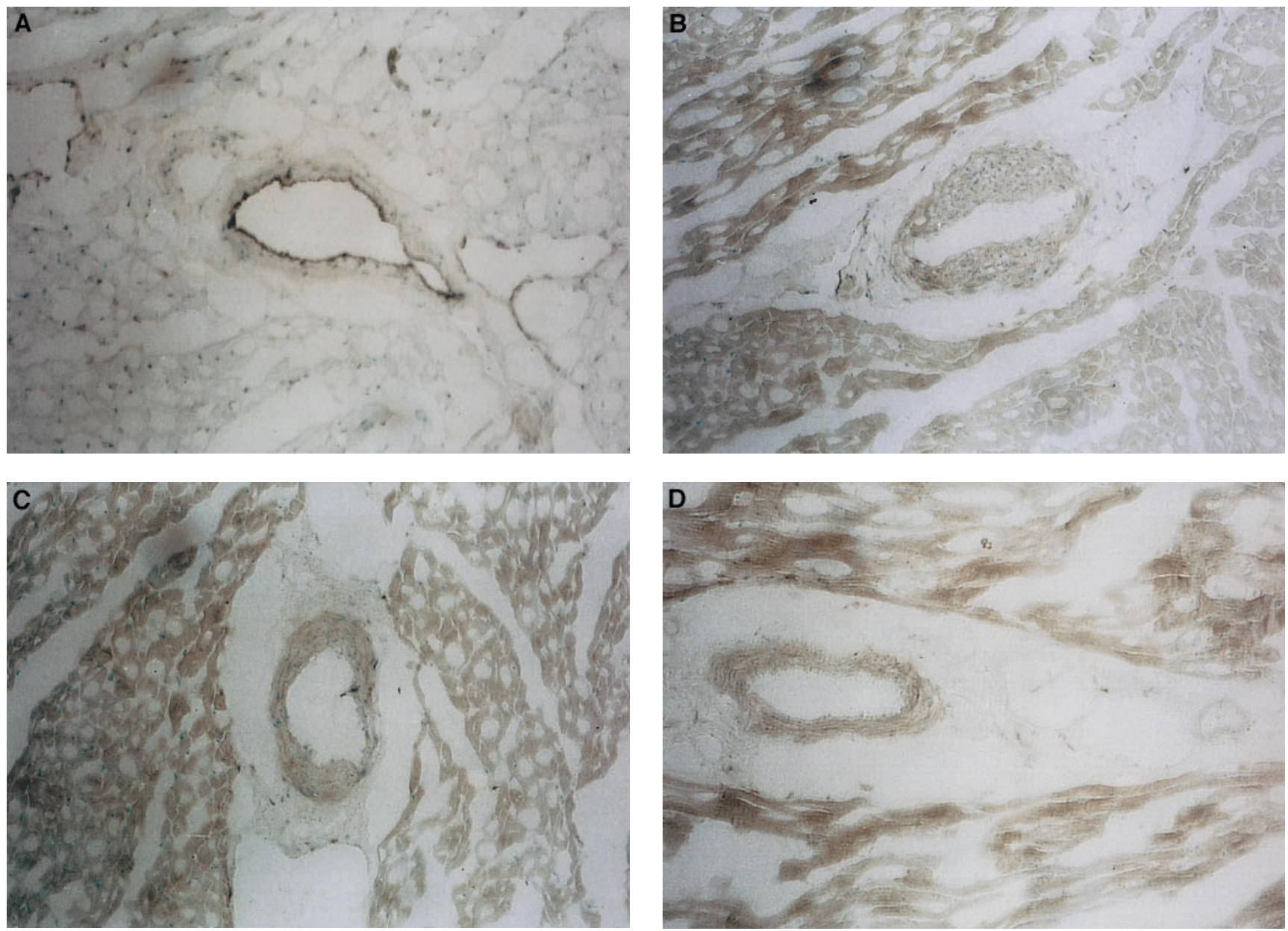

Figure 8. Representative photomicrographs showing immunohistochemical staining for P-selectin in $(A)$ myocardium after 90 min of occlusion followed by $20 \mathrm{~min}$ of reperfusion; $(B)$ myocardium perfused by the LAD in the control group; $(C)$ myocardium perfused by the LCX in the control group; $(D)$ myocardium perfused by the LAD in the 8-SPT group. Original magnification $\times 400$. The immunostaining for P-selectin in endothelium was prominent in $A$. No or weak staining for P-selectin was found in $B-D$.

and metabolism of myocardium, respectively. Since mAb against P-selectin attenuated the decreases in FS and LER, deteriorations of contractile and metabolic functions of myocardium were mainly due to the formation of thromboemboli. However, the inhibition of the formation of thromboemboli by $\mathrm{mAb}$ against $\mathrm{P}$-selectin did not restore completely the myocardial dysfunctions induced by 8 -SPT. This finding suggests that multifactorial functions of endogenous adenosine may act synerigistically to improve the contractile and metabolic function of the myocardium during coronary hypoperfusion.

The intracoronary administration of 8-SPT did not affect the baseline coronary hemodynamic variables, consistent with a previous report (28). This finding suggests that 8-SPT did not have any effect on coronary circulation under baseline conditions. It is likely that adenosine plays a minimal role in coronary circulation under baseline conditions, or that vasoactive substances other than adenosine play a compensatory role when the adenosine receptors are blocked (28).

Role of P-selectin in thromboemboli during hypoperfusion. The blockade of adenosine receptors by 8-SPT during coronary hypoperfusion led to the formation of thromboemboli. Implicated elements of thromboemboli are leukocytes that adhere to the endothelium, leukocyte-platelet conjugates, platelet aggregates, fibrin clots, and red blood cell rouleaux formation (16). Quantitative analysis revealed that coronary arterioles were occupied $>90 \%$ by thromboemboli in the ischemic myocardium treated with 8-SPT. We demonstrated that $\mathrm{mAb}$ against $\mathrm{P}$-selectin attenuated the formation of thromboemboli induced by 8-SPT, suggesting that expression of P-selectin on platelets and/or on endothelial cells plays an important role in the formation of thromboemboli during coronary hypoperfusion. We have confirmed that P-selectin was not expressed on endothelial cells during coronary hypoperfusion in the presence and absence of 8-SPT. In contrast, the expression of P-selectin on platelets and neutrophil-platelet adhesion, which was mediated by P-selectin, were increased during coronary hypoperfusion when the adenosine receptors were blocked. These findings suggest that P-selectin on platelets and/or neutrophil-platelet conjugates mediated by P-selectin, and not the endothelium, may play the major role in the formation of thromboemboli. Although this study did not demonstrate direct evidence for whether or how P-selectin on platelets and/or neutrophil-platelet conjugates mediated by P-selectin develop the thromboemboli in coronary vessels, there are sev- 
A
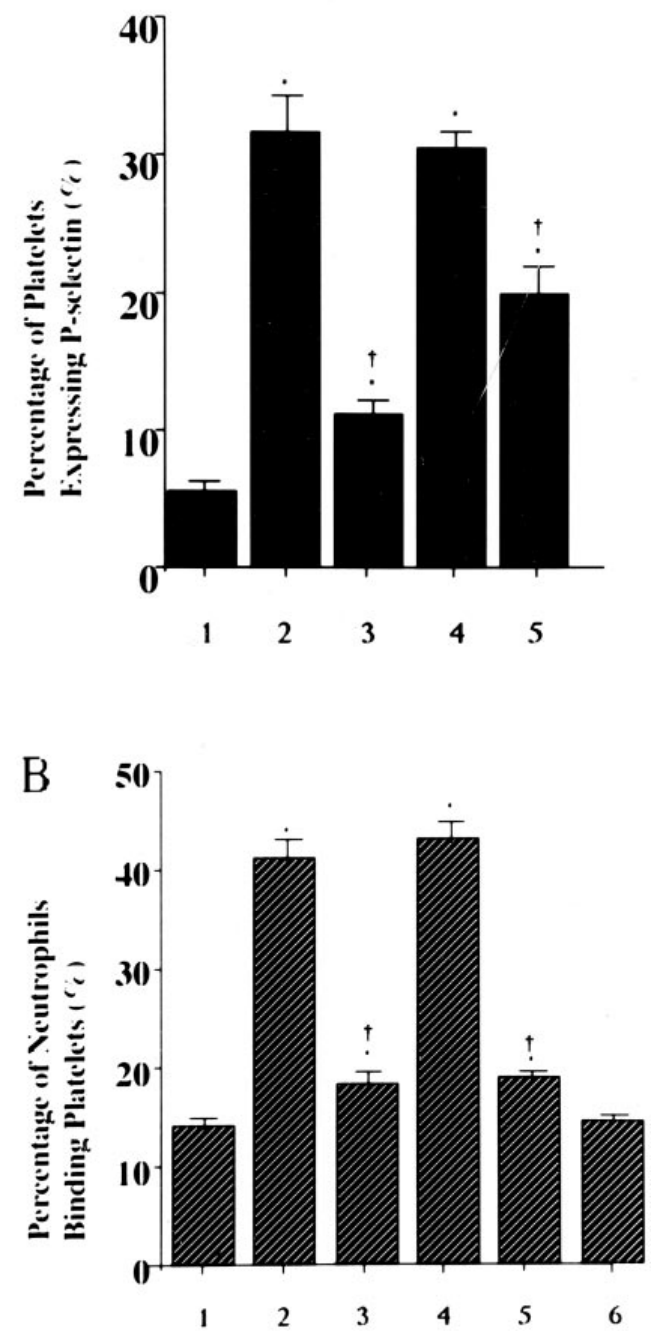

Figure 9. Effects of pretreatment of either adenosine, CHA, or CGS21680C on the thrombin $(0.1 \mathrm{U} / \mathrm{ml})$-induced increase in the percentage of platelets that expressed P-selectin and of neutrophils that bound to platelets. 1 , Control. 2, Thrombin $(0.1 \mathrm{U} / \mathrm{ml})$. 3, Adenosine $\left(10^{-5} \mathrm{~mol} /\right.$ liter $) .4$, CHA $\left(10^{-8} \mathrm{~mol} / \mathrm{liter}\right) .5$, CGS21680 C $\left(10^{-8} \mathrm{~mol} /\right.$ liter). 6, CY1747 (10 $\mu \mathrm{g} / \mathrm{ml})$. Adenosine and CGS21680, not CHA, inhibited the thrombin-induced expression of P-selectin and neutrophil-platelet adhesion. CY1747 inhibited neutrophil-platelet adhesion. Each bar represents the mean \pm SEM of five distinct experiments. ${ }^{*} P<0.05$ vs. $1 ;{ }^{\dagger} P<0.05$ vs. 2 .

eral possible mechanisms by which they may lead to the formation of thromboemboli. One possibility is that the activation of platelets results in adhesion to the endothelial cells (12, 27). The leukocytes accumulate within the thromboemboli via P-selectin expressed on platelets $(12,29)$. A second possibility is that the adhesion of platelets to neutrophils activates neutrophils (30). Activated leukocytes release vasoactive substances that damage the myocardium and endothelium (31), induce the vasoconstriction of the coronary artery (22), and even obstruct the small vessels (13). Once the activated leukocytes are trapped in small vessels, restoration of normal perfusion pressure may fail to dislodge the leukocytes (32). A third possibil- ity is that neutrophil-platelet conjugates became trapped in the small vessels of the coronary circulation. The size of such conjugates can increase progressively as a consequence of the aggregation of homotypic leukocytes and of neutrophil-platelet conjugates (33). The neutrophil-platelet conjugates may become large enough to obstruct the coronary small vessels.

Neutrophil-platelet adhesion can occur by several mechanisms, including fibrinogen bridges, thrombospondin bridges, and the P-selectin-mediated adhesion of platelets to neutrophils (34). Kurose et al. reported that $\mathrm{mAb}$ against P-selectin reduces neutrophil-platelet adhesion by $80 \%$ in ischemia/ reperfused tissues (33). The present study demonstrated that $\mathrm{mAb}$ against $\mathrm{P}$-selectin suppressed the increase in the percentage of neutrophils that bound to platelets induced by 8-SPT; P-selectin on platelets plays a major role in such neutrophilplatelet adhesion. The adhesion of neutrophils to P-selectinpositive platelets causes functional changes in neutrophils, such as CD11b upregulation (30) and oxidative burst (35). Further investigation is needed to clarify the physiological relevance of neutrophil-platelet adhesion.

Effects of adenosine on expression of $P$-selectin and formation of neutrophil-platelet conjugates. This study demonstrated that the intracoronary administration of 8-SPT increased the percentage of platelets that expressed P-selectin and of neutrophils that bound to platelets during coronary hypoperfusion, which suggests that increased levels of adenosine during coronary hypoperfusion may inhibit the expression of P-selectin on platelets and neutrophil-platelet adhesion. This study demonstrated that adenosine directly inhibited the thrombin-induced increases in the expression of P-selectin on platelets and neutrophil-platelet conjugates in the in vitro experiments. The dose of thrombin used in the in vitro experiments induced the expression of P-selectin on platelets and neutrophil-platelet adhesion comparable to those in the in vivo experiments. The level of adenosine during coronary hypoperfusion was $\sim 4 \times$ $10^{-7} \mathrm{~mol} /$ liter. Since adenosine is produced by endothelial cells, smooth muscle cells, and cardiomyocytes $(1,2)$, the topical level of adenosine near the endothelium, where platelets, neutrophils, and endothelium interact with each other, may be much higher. We demonstrated that the level of adenosine that would be attainable during coronary hypoperfusion attenuated the thrombin-induced increase in the expression of P-selectin on platelets and the formation of neutrophil-platelet conjugates. Although we could not exclude the possibility that a deterioration of myocardial function due to the blockade of adenosine receptors may increase the expression of $\mathrm{P}$-selectin on platelets and neutrophil-platelet adhesion in the in vivo experiments, the results of the in vitro experiments suggested that increased levels of adenosine during coronary hypoperfusion may directly inhibit the expression of P-selectin on platelets and the binding of neutrophils to platelets, resulting in the suppression of the formation of thromboemboli in the ischemic myocardium. Adenosine is known to modulate platelet function via adenosine $\mathrm{A}_{2}$ receptors (36). The dose of CGS21680C used in the present study was specific for the adenosine $\mathrm{A}_{2}$ receptors $(21,22)$. Since we demonstrated that adenosine and CGS21680C, not CHA, an adenosine $\mathrm{A}_{1}$ agonist, reduced the expression of P-selectin and neutrophil-platelet adhesion, effects of adenosine occur mainly via adenosine $\mathrm{A}_{2}$ receptors. Since adenosine $A_{2}$ receptors are also present on neutrophils (37), effects of adenosine on neutrophils might contribute to the reduction of neutrophil-platelet adhesion. 
A possible confounding factor in this study was the use of a bypass tube to reduce CBF. Rinder et al. demonstrated that cardiopulmonary bypass induces neutrophil-platelet adhesion in patients who are undergoing this procedure (38). However, we found no significant difference between the extent of neutrophil-platelet adhesion before and $30 \mathrm{~min}$ after the insertion of the bypass tube, and no thrombosis occurred in the control group. Furthermore, since blood was withdrawn from the bypass tube immediately proximal to the insertion point to the LAD and from the coronary vein, we were able to evaluate the changes in expression of P-selectin on platelets and neutrophil-platelet adhesion within the hearts.

Flow cytometric analysis showed that both the percentage of platelets that expressed P-selectin and the percentage of neutrophils that bound to platelets in the circulating blood were $\sim 25 \%$. Since activated platelets and neutrophil-platelet conjugates may adhere to the walls of the blood vessel, the actual percentages of activated platelets and of neutrophil-platelet conjugates would be higher than that evaluated by flow cytometric analysis.

Clinical implications. Recent clinical findings demonstrate that platelets that expressed P-selectin increased in patients with myocardial infarction (23) and those with unstable angina (39). Since $\mathrm{mAb}$ against $\mathrm{P}$-selectin prevented the formation of thromboemboli during coronary hypoperfusion and improved contractile and metabolic dysfunction of the myocardium, the inhibition of the expression of P-selectin on platelets presents a potential strategy for treating patients with coronary artery disease. Recent studies demonstrated that the administration of adenosine reduces the size of myocardial infarct (40), improves cardiac function, and prevents the no-reflow phenomenon (41) in patients with acute myocardial infarction. The results of the present study suggest that one of the beneficial effects of adenosine might be mediated by its inhibitory effects on neutrophil-platelet adhesion and the expression of P-selectin on platelets in these patients. To our knowledge, there are no clinical reports that depressed levels of endogenous adenosine contribute to the extension of myocardial ischemia/ reperfusion injury and thrombotic episodes in patients with coronary artery disease. Since the main site of adenosine production in the heart is the endothelium, which is impaired in patients with coronary artery disease and those with risk factors for it (42), adenosine production might be impaired in these patients. Further investigations are needed to clarify the pathophysiological role of endogenous adenosine and the regulation of adenosine production in clinical settings. Finally, Ott et al. reported an increase in neutrophil-platelet adhesion in patients with unstable angina (30). Although it has not been determined whether neutrophil-platelet adhesion merely reflects the activation of P-selectin on platelets or whether it has relevance to the pathophysiology of coronary artery disease, the use of pharmacological interventions that target the inhibition of neutrophil-platelet adhesion may have major implications for developing new therapeutic strategies.

\section{Acknowledgments}

We thank Ms. Kayoko Yoshida and Sachiyo Nomura for excellent technical assistance.

T. Minamino is a Research Fellow of the Japan Society for the Promotion of Science (JSPS) for Young Scientists. This study was supported by a grant-in-aid for JSPS Fellows from the Japanese Min- istry of Education, Science and Culture, and by a Japan Heart Foundation-Pfizer Pharmaceuticals grant for research on coronary artery disease.

\section{References}

1. Hori, M., and M. Kitakaze. 1991. Adenosine, the heart, and coronary circulation. Hypertension (Dallas). 18:565-574.

2. Engler, R.L., and H.E. Gruber. 1992. Adenosine: an autacoid. In The Heart and Cardiovascular System. H.A. Fozzard, editor. Raven Press, Ltd., New York. 92-105.

3. Minamino, T., M. Kitakaze, T. Morioka, K. Node, Y. Shinozaki, M Chujo, H. Mori, H. Takeda, M. Inoue, M. Hori, and T. Kamada. 1995. Bidirectional effects of aminophylline on myocardial ischemia. Circulation. 92:12541260.

4. Kitakaze, M., M. Hori, H. Sato, S. Takashima, M. Inoue, A. Kitabatake, and T. Kamada. 1991. Endogenous adenosine inhibits platelet aggregation during myocardial ischemia in dogs. Circ. Res. 69:1402-1408.

5. Pitarys II, C.J., R. Virmani, H.D. Vildibill, Jr., E.K. Jackson, and M.B Forman. 1991. Reduction of myocardial reperfusion injury by intravenous adenosine administered during the early reperfusion period. Circulation. 83:237-247.

6. Bullough, D.A., M.J. Magill, G.S. Firestein, and K.M. Mullane. 1995. Adenosine activates $\mathrm{A}_{2}$ receptors to inhibit neutrophil adhesion and injury to isolated cardiac myocytes. J. Immunol. 155:2579-2586.

7. Kishimoto, T.K., and R. Rothlein. 1994. Integrins, ICAMs, and selectins: role and regulation of adhesion molecules in neutrophil recruitment to inflammatory sites. Adv. Pharmacol. 25:117-169.

8. Ware, J.A., and D.D. Heistad. 1993. Platelet-endothelium interactions N. Engl. J. Med. 328:628-635.

9. Lefer, A.M., A.S. Weyrich, and M. Buerke. 1994. Role of selectins, a new family of adhesion molecules, in ischemia-reperfusion injury. Cardiovasc. Res. 28:289-294.

10. Hamburger, S.A., and R.P. McEver. 1990. GMP-140 mediates adhesion of stimulated platelets to neutrophils. Blood. 75:550-554.

11. Ley, K., and T.F. Tedder. 1995. Leukocyte interactions with vascular endothelium: new insights into selectin-mediated attachment and rolling. J. Immunol. 155:525-528.

12. Palabrica, T., R. Lobb, B.C. Furie, M. Aronovitz, C. Benjamin, Y.M. Hsu, S.A. Sajer, and B. Furie. 1992. Leukocyte accumulation promoting fibrin deposition is mediated in vivo by P-selectin on adherent platelets. Nature. 359: 848-851.

13. Engler, R.L., G.W. Schmid-Schönbein, and R.S. Pavelec. 1983. Leukocyte capillary plugging in myocardial ischemia and reperfusion in the dog. Am. J. Pathol. 111:98-111.

14. Scheridan, F.M., P.G. Cole, and D. Ramage. 1996. Leukocyte adhesion to coronary microvasculature during ischemia and reperfusion in an in vivo canine model. Circulation. 93:1784-1787.

15. Weyrich, A.S., X.I. Ma, D.J. Lefer, K.H. Albertine, and A.M. Lefer. 1993. In vivo neutralization of P-selectin protects feline heart and endothelium in myocardial ischemia and reperfusion injury. J. Clin. Invest. 88:1396-1406.

16. Jerome, S.N., M. Doré, J.C. Paulson, C.W. Smith, and R.J. Korthuis 1994. P-selectin and ICAM-1-dependent adherence reactions: role in the genesis of postischemic no-reflow. Am. J. Physiol. 266:H1316-H1321.

17. Packham, M.A., N.G. Ardlie, and J.F. Mustard. 1969. Effects of adenine compounds on platelet aggregation. Am. J. Physiol. 217:1009-1017.

18. Cronstein, B.N., R.I. Levin, R. Hirschhorn, S.B. Abramson, and G. Weissmann. 1992. Neutrophil adherence to endothelium is enhanced via adenosine $\mathrm{A}_{1}$ receptors and inhibited via adenosine $\mathrm{A}_{2}$ receptors. J. Immunol. 148: 2201-2206.

19. Lefer, D.J., D.M. Flynn, and A.J. Buda. 1996. Effects of a monoclonal antibody directed against P-selectin after myocardial ischemia and reperfusion. Am. J. Physiol. 270:H88-H98.

20. Cobbold, S., and S. Metcalfe. 1994. Monoclonal antibodies that define canine homologues of human CD antigens: summary of the First International Canine Leukocyte Antigen Workshop (CLAW). Tissue Antigens. 43:137-154.

21. Varani, K., S. Gessi, A. Dalpiaz, and P.A. Borea. 1996. Pharmacological and biochemical characterization of purified A2a adenosine receptors in human platelet membranes by $\left[{ }^{3} \mathrm{H}\right]-\mathrm{CGS} 21680$ binding. Br. J. Pharmacol. 117:16931701.

22. Minamino, T., M. Kitakaze, K. Node, H. Funaya, M. Inoue, M. Hori, and T. Kamada. 1996. Adenosine inhibits leukocyte-induced vasoconstriction. Am. J. Physiol. H2622-H2628.

23. Langford, E.J., R.J. Wainwright, and J.F. Martin. 1996. Platelet activation in acute myocardial infarction and unstable angina is inhibited by nitric oxide donors. Arterioscler. Thromb. Vasc. Biol. 16:51-55.

24. Rinder, H.M., J.L. Bonan, C.S. Rinder, K.A. Ault, and B.R. Smith. 1991. Dynamics of leukocyte-platelet adhesion in whole blood. Blood. 78:17301737.

25. Gawaz, M.P., S.K. Mujais, B. Schmidt, and H.J. Gurland. 1994. Plateletleukocyte aggregation during hemodialysis. Kidney Int. 46:489-495.

26. Tomanek, R.J., P.J. Palmer, G.L. Peiffer, K.L. Schreiber, C.L. Eastham, 
and M.L. Marcus. 1986. Morphometry of canine coronary arteries, arterioles, and capillaries during hypertension and left ventricular hypertrophy. Circ. Res. 58:38-46.

27. Hawkins, H.K., M.L. Entman, J.Y. Zhu, K.A. Youker, K. Berens, M. Doré, and C.W. Smith. 1996. Acute inflammatory reaction after myocardial ischemic injury and reperfusion. Am. J. Pathol. 148:1957-1969.

28. Duncker, D.J., N.S. van Zon, Y. Ishibashi, and R.J. Bache. 1996. Role of $\mathrm{K}^{+}$-ATP channels and adenosine in the regulation of coronary blood flow during exercise with normal and restricted coronary blood flow. J. Clin. Invest. 97: 996-1009.

29. Doré, M., S.I. Simon, B.J. Hughes, M.L. Entman, and C.W. Smith. 1995. P-selectin- and CD18-mediated recruitment of canine neutrophils under conditions of shear stress. Vet. Pathol. 32:258-268.

30. Ott, I., F.J. Neumann, M. Gawaz, M. Schmitt, and A. Schömig. 1996. Increased neutrophil-platelet adhesion in patients with unstable angina. Circulation. 94:1239-1246.

31. Lucchesi, B.R. 1990. Modulation of leukocyte-mediated myocardial reperfusion injury. Annu. Rev. Physiol. 52:561-576.

32. Bagge, U., B. Ammundson, and C. Lauritzen. 1980. White blood cell deformability and plugging of skeletal muscle capillaries in hemorrahagic shock. Acta Physiol. Scand. 108:159-163.

33. Kurose, I., D.C. Anderson, M. Miyasaka, T. Tamatani, J.C. Paulson, R.F. Todd, J.R. Rusche, and D.N. Granger. 1994. Molecular determinants of reperfusion-induced leukocyte adhesion and vascular protein leakage. Circ. Res. 74:336-343.

34. Entman, M.L., and C.M. Ballantyne. 1996. Association of neutrophils with platelet aggregates in unstable angina. Should we alter therapy? Circula- tion. 94:1206-1208.

35. Nagata, K., T. Tsuji, N. Todoroki, Y. Katagiri, K. Tanoue, H. Yamazaki, N. Hanai, and T. Irimura. 1993. Activated platelets induce superoxide anion release by monocytes and neutrophils through P-selectin (CD62). J. Immunol. 151:3267-3276.

36. Feoktistov, I., and I. Biaggioni. 1993. Characterization of adenosine receptors in human erythroleukemia cells and platelets: further evidence for heterogeneity of adenosine $A_{2}$ receptor subtypes. Mol. Pharmacol. 43:909-914.

37. Cronstein, B.N., L. Duguma, D. Nichols, A.J. Hutchison, and M. Williams. 1990. The adenosine/neutrophil paradox resolved: human neutrophils possess both $\mathrm{A}_{1}$ and $\mathrm{A}_{2}$ receptors that promote chemotaxis and inhibit $\mathrm{O}_{2}^{-}$generation, respectively. J. Clin. Invest. 85:1150-1157.

38. Rinder, C.S., J.L. Bonan, H.M. Rinder, J. Mathew, R. Hines, and B.R. Smith. 1992. Cardiopulmonary bypass induces leukocyte-platelet adhesion. Blood. 79:1201-1205.

39. Ikeda, H., Y. Takajo, K. Ichiki, T. Ueno, S. Maki, T. Noda, K. Sugi, and T. Imaizumi. 1995. Increased soluble form P-selectin in patients with unstable angina. Circulation. 92:1693-1696.

40. Mahaffeg, K.M., J.A. Puma, A. Barbagelata, C.A. Casas, L. Lambe, C. Orlandi, R.J. Gibbsons, R.M. Califf, and C.B. Granger. 1997. Dose adenosine in conjugation with thrombolysis reduce infarct size? Results from the controlled, randomized AMISTAD trial. Circ. Suppl. 96:I206-I207. (Abstr.)

41. Marzilli, M., E. Gliozheni, S. Fedele, I. Ungi, E. Orsini, and P. Marraccini. 1997. Beneficial effects of adenosine in acute myocardial infarction. J. Am. Coll. Cardiol. 29:133A. (Abstr.)

42. Abrams, J. 1997. Role of endothelial dysfunction in coronary artery disease. Am. J. Cardiol. 79:2-9 